\title{
Surgical repair of persistent fifth aortic arch coarctation and interrupted fourth aortic arch without cardiopulmonary bypass: a case report
}

\author{
Xiaobing Li, Jia Li, Wenjun Qin, Rufang Zhang \\ Department of Pediatric Cardiothoracic Surgery, Shanghai Children's Hospital, Shanghai Jiao Tong University, Shanghai, China \\ Correspondence to: Rufang Zhang. Department of Pediatric Cardiothoracic Surgery, Shanghai Children's Hospital, Shanghai Jiao Tong University, \\ Shanghai 200062, China. Email: shydlxb@163.com.
}

\begin{abstract}
Persistent fifth aortic arch (PFAA) is a rare congenital cardiovascular anomaly of the aortic arch, which can occur independently but is frequently associated with other cardiovascular malformations including patent ductus arteriosus (PDA), interrupted aortic arch (IAA), pulmonary atresia, tetralogy of Fallot, and transposition of the great vessels. PFAA can be classified into three different types according to different abnormal vascular connections (type A, B and C). We report an infant diagnosed with PFAA along with interrupted fourth aortic arch (type B) and PDA. Several surgical methods have been delivered to patients diagnosed with PFAA. In our case, the correction of coarctation PFAA and the ligation of PDA were performed without cardiopulmonary bypass through left lateral thoracotomy. We removed the coarctation part of the PFAA, and then performed the end-to-end anastomosis between the fifth aortic arch and the descending aorta. Despite the stenosis at the site of anastomosis was observed 10 months after the operation, the patient resulted in good recovery by once balloon dilation procedure. Thus, we recommend it is more appropriable to select this procedure in the surgical treatment of PFAA for those patients whose fourth aortic arches were interrupted with fifth aortic arches well developed. Our experience can provide a beneficial reference for future cases.
\end{abstract}

Keywords: Persistent fifth aortic arch (PFAA); interrupted fourth aortic arch; coarctation resection; end-to-end anastomosis; case report

Submitted Aug 03, 2021. Accepted for publication Dec 15, 2021.

doi: $10.21037 /$ tp-21-350

View this article at: https://dx.doi.org/10.21037/tp-21-350

\section{Introduction}

Persistent fifth aortic arch (PFAA) is a very rare congenital cardiovascular defect, which is often associated with other cardiovascular anomalies such as patent ductus arteriosus (PDA), interrupted aortic arch (IAA), pulmonary atresia, tetralogy of Fallot, and transposition of the great vessels. PFAA was first described by Van Praagh in an autopsy specimen in 1969 (1). PFAA is an abnormal vessel, arising from the ascending aorta proximal to the origin of the brachiocephalic artery, and then terminating in the dorsal aorta or pulmonary artery via the patent arterial duct, which was defined comprehensively by Gupta (2). We report the case of an infant diagnosed with PFAA, IAA and patent arterial duct. We present the following case in accordance with the CARE reporting checklist (available at https:// tp.amegroups.com/article/view/10.21037/tp-21-350/rc).

\section{Case presentation}

A 50-day-old male infant who weighed $4.7 \mathrm{~kg}$ was admitted to our hospital because of suffering from shortness of breath for more than 10 days. This male infant was the first child from a nonconsanguineous couple without family history. Although his vital signs were stable, a grade 1/6 ejection systolic murmur was observed at the $2 \mathrm{nd}$ or $3 \mathrm{rd}$ left parasternal intercostal space without accentuation 

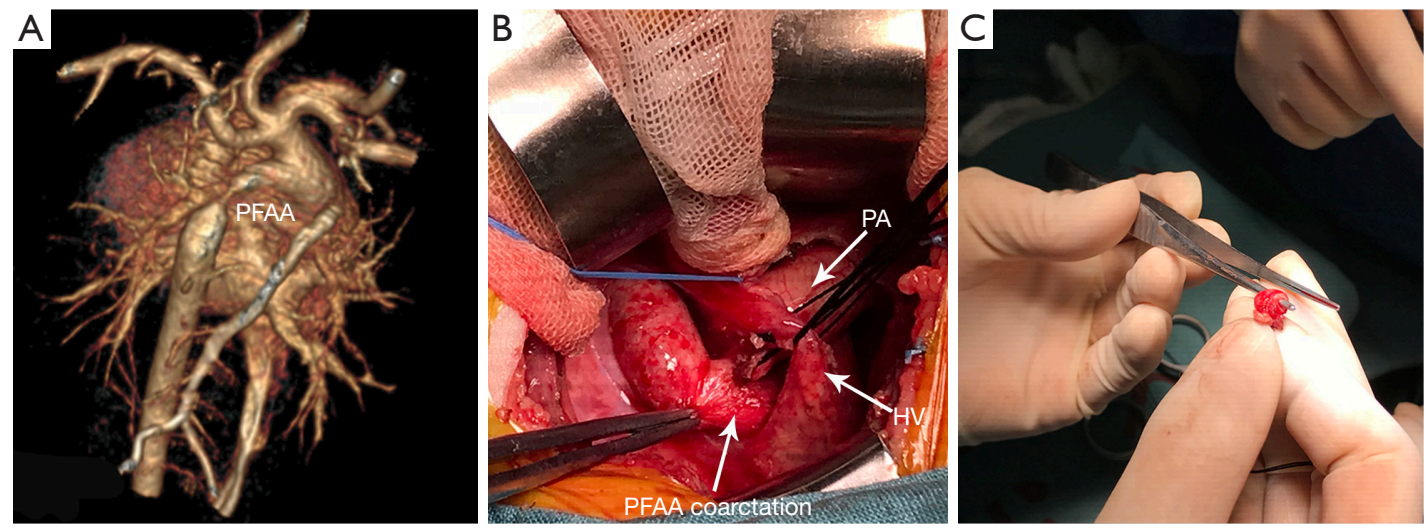

Figure 1 CTA and surgical photograph of this patient. (A) CTA before the operation; (B) surgical photograph in the operation; (C) the resection part of the PFAA coarctation. This image is published with the consent from the patient's parents or legal guardians. CTA, computed tomography angiography; PFAA, persistent fifth aortic arch; PA, pulmonary artery; HV, hemiazygos vein.

pulmonary components of the second heart sound. Furthermore, his blood pressures in upper limbs (left $103 / 56 \mathrm{mmHg}$, right $101 / 54 \mathrm{mmHg}$ ) were significantly higher than those in lower limbs (left $60 / 45 \mathrm{mmHg}$, right $59 / 46 \mathrm{mmHg}$ ). Electrocardiogram displayed sinus rhythm and Q-T intervals prolonged. IAA (type A), PDA, PFAA with a coarctation, and the left vertebral artery (LVA) arising behind the fourth AA were observed in echocardiography and computed tomography angiography (CTA) (Figure 1A).

Surgical repair was performed through the left anterolateral fourth intercostal thoracotomy incision in the right lateral position. The arterial duct was $3 \mathrm{~mm}$ in diameter, which was ligated and then disconnected (Figure 1B). The PFAA and descending aorta were crossclamped. Then the narrowest part of the PFAA was excised which was about $5 \mathrm{~mm}$ long (Figure $1 C$ ), and then an endto-end anastomosis was conducted. As shown in Figure 2, the diagram can display the procedure of the surgical repair. The anastomotic aorta was $8 \mathrm{~mm}$ in diameter, with blood pressure at $90 / 49 \mathrm{mmHg}$ in upper right limb and $75 / 49 \mathrm{mmHg}$ in lower right limb. Echocardiography showed that the cardiac function was normal and the blood flow in anastomotic aorta was smooth after the surgery. The patient resulted in good recovery and was discharged on day 7th post operation. A stenosis was identified by CTA at 10 months after the resection (Figure 3A). Eighteen months after the resection, the stenosis still remained (Figure 3B), and then the balloon dilation procedure through cardiac catheterization was conducted. Pre-dilation invasive blood pressure difference was $23 \mathrm{mmHg}$ between anterior stenosis site $(93 / 66 \mathrm{mmHg})$ and posterior stenosis site
(70/56 $\mathrm{mmHg}$ ), but post-dilation invasive blood pressure difference was $4 \mathrm{mmHg}$. In the latest follow-up visit 2 years after the balloon dilation, the echocardiography revealed the diameter of the anastomotic part was $6.5 \mathrm{~mm}$, almost the same diameter as aortic arch. The blood pressure difference between anterior anastomotic site and posterior anastomotic site was $16 \mathrm{mmHg}$, with blood pressure at $100 / 70 \mathrm{mmHg}$ in upper right limb and $105 / 72 \mathrm{mmHg}$ in lower right limb. CTA at the postoperative follow-up showed a good recovery with normal cardiac function 3 years (Figure 3C) and 4 years (Figure 3D) after the resection.

All procedures performed in studies involving human participants were in accordance with the ethical standards of the institutional and/or national research committee(s) and with the Helsinki Declaration (as revised in 2013). Written informed consent was obtained from the patient's parents or legal guardians for publication of this case report and accompanying images. A copy of the written consent is available for review by the editorial office of this journal.

\section{Discussion}

PFAA is a very rare congenital cardiovascular anomaly (3). It is an extrapericardial vessel arising from the ascending aorta, and then connecting to the systemic or pulmonary circulation. PFAA is most commonly classified into three different types according to its different aberrant vascular connections, described by Weinberg (4). PFAA can be subdivided into two major types: systemic-to-systemic (type $\mathrm{A}$ and $\mathrm{B}$ ) and systemic-to-pulmonary (type C) connection. There is a double-lumen aortic arch in type A PFAA. The 

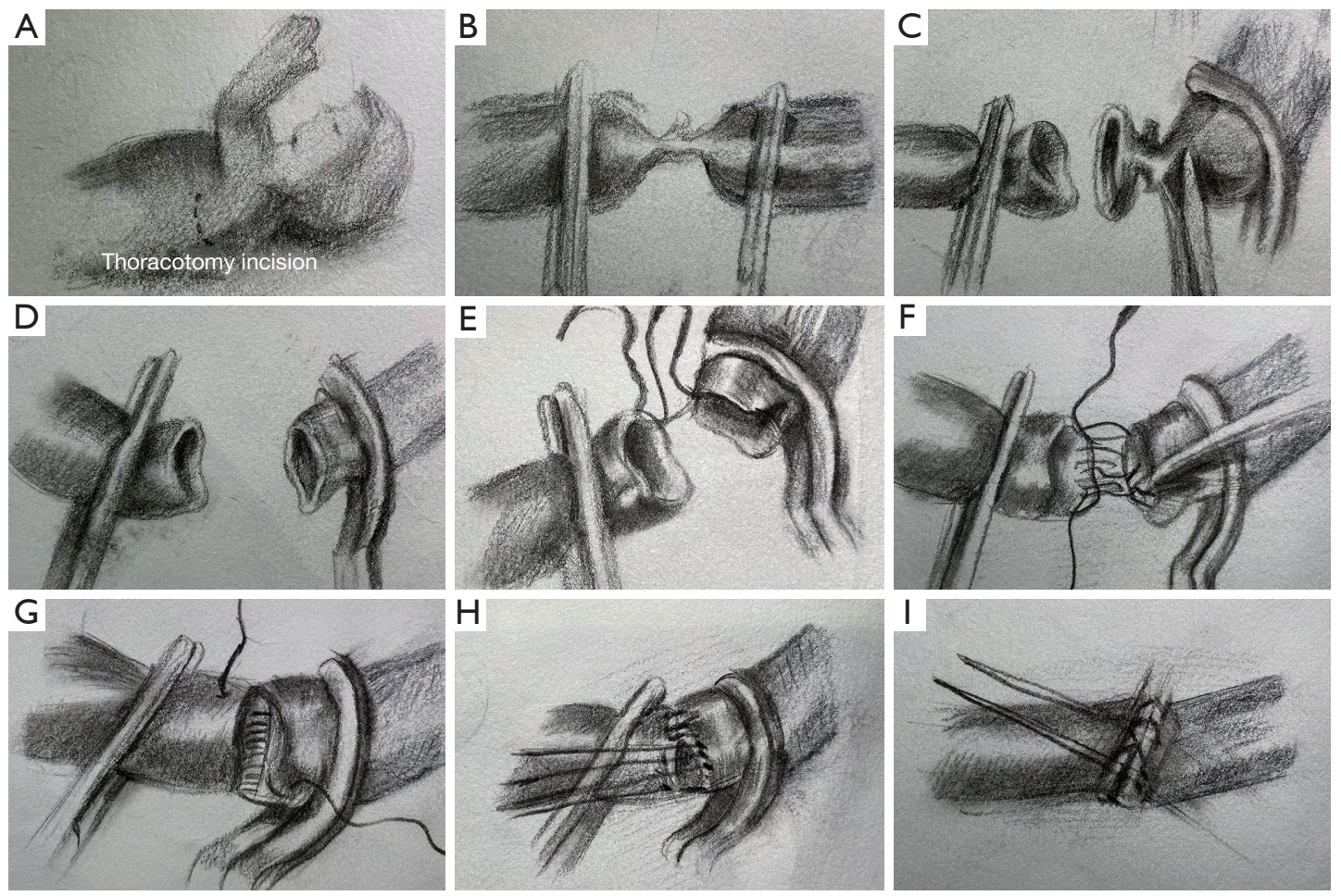

Figure 2 A diagram of the procedure about the surgical repair in this patient. (A) The child in the right lateral position with the left anterolateral fourth intercostal thoracotomy incision; (B) clamping the proximal stenosis site and distal stenosis site of the PFAA; (C) excising the stenosis part; (D) the proximal and distal aorta with the stenosis resected; (E) conducting the end-to-end anastomosis; (F) suturing the vessel; $(\mathrm{G})$ half of the vessel sutured; (H) continuing to suture the vessel; (I) the suture finished. PFAA, persistent fifth aortic arch.

fourth $\mathrm{AA}$ is above the fifth $\mathrm{AA}$, running parallel to each other, and connecting the ascending and descending aorta. In type B PFAA, the fourth AA is interrupted or atretic, only the fifth AA connects the ascending and descending aorta. The fourth AA is interrupted, and the fifth AA arises from the origin of the brachiocephalic artery and connects to the pulmonary artery, which is described as type C PFAA. According to the classification, our case was classified as type B PFAA with coarctation.

Cardiac MRI and CTA are the reference standards for the diagnosis of PFAA. With the development of the threedimensional angiography imaging, the multi-slice spiral CTA (MSCTA) which can display the PFAA clearly and directly is widely used in recent years. Several surgical procedures have been used to repair the coarctation of PFAA including patch enlargement of the coarctation, using tube grafts and end-to-end anastomosis between the descending aorta and the fifth AA (5). The fourth AA in our case was interrupted. Four vessels arose directly from the ascending aorta. And the fifth AA was well developed. Therefore, we resected the coarctation of the fifth AA, and then conducted an end-to-end anastomosis. There was no intra-cardiac malformation in this infant, so we performed the surgery through the left anterolateral fourth intercostal thoracotomy incision in the right lateral position without cardiopulmonary bypass. In this way, it can provide clear operative field, and the infant can also benefit from less trauma, less bleeding and better appearance. The infant recovered smoothly after this simple and short-time operation. Despite a stenosis was observed at anastomotic part at 10 months after the operation. The infant recovered well after once balloon dilation procedure, and no occurrence of the stenosis was observed in the followed 2 years. Through our surgical experience, we believe that this surgical procedure is more suitable for such patient whose fifth AA well developed. And this child's patients appreciated the doctors very much for the appropriate treatments of their child. 

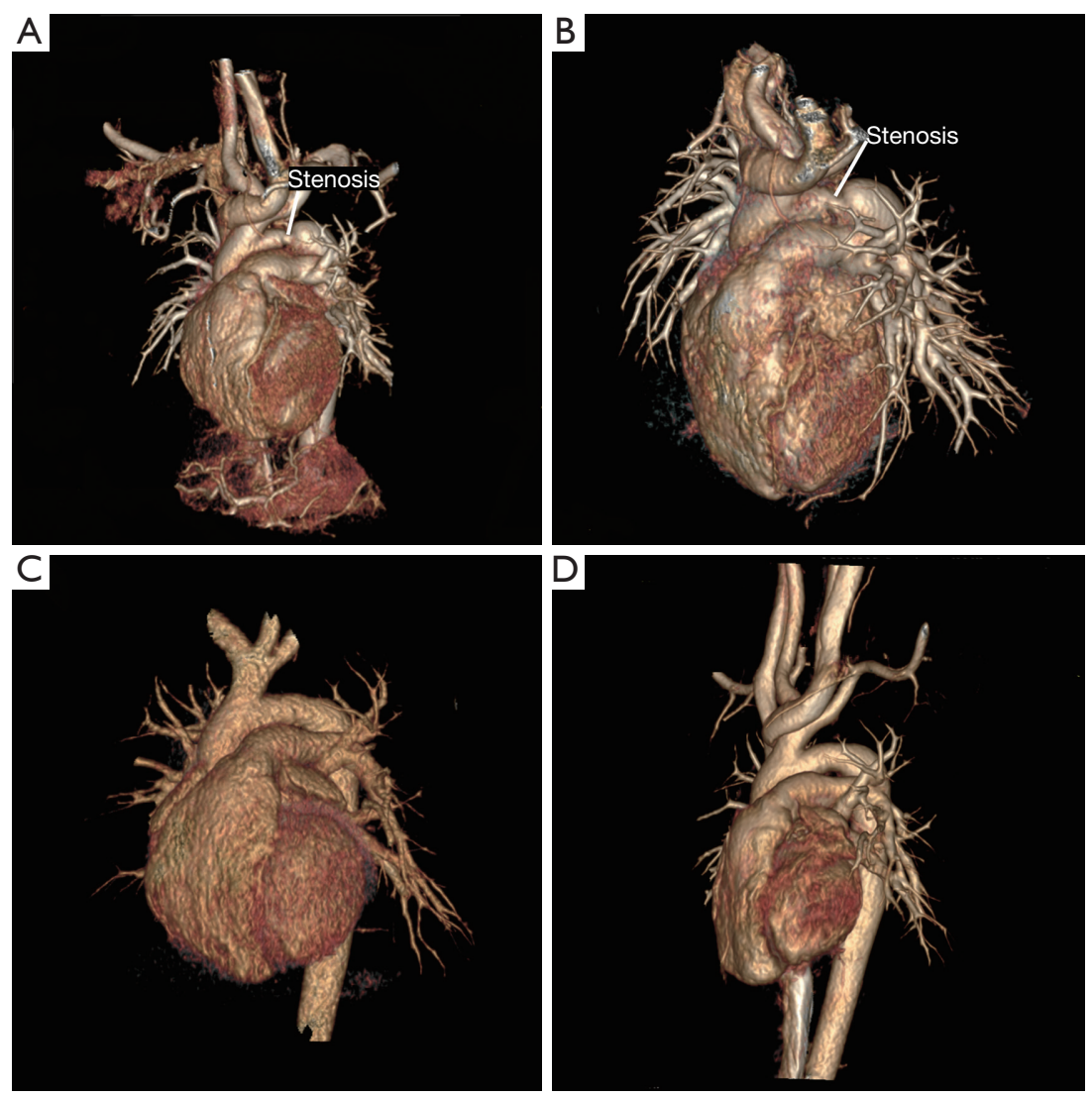

Figure 3 Follow-up CTA of this patient. (A) CTA 10 months after the operation; (B) CTA 18 months after the operation; (C) CTA 18 months after the balloon dilation procedure; (D) CTA 30 months after the balloon dilation procedure. This image is published with the consent from the patient's parents or legal guardians. CTA, computed tomography angiography.

\section{Acknowledgments}

Funding: None.

\section{Footnote}

Reporting Checklist: The authors have completed the CARE reporting checklist. Available at https://tp.amegroups.com/ article/view/10.21037/tp-21-350/rc

Conflicts of Interest: All authors have completed the ICMJE uniform disclosure form (available at https://tp.amegroups. com/article/view/10.21037/tp-21-350/coif). The authors have no conflicts of interest to declare.

Ethical Statement: The authors are accountable for all aspects of the work in ensuring that questions related to the accuracy or integrity of any part of the work are appropriately investigated and resolved. All procedures performed in studies involving human participants were in accordance with the ethical standards of the institutional and/or national research committee(s) and with the Helsinki Declaration (as revised in 2013). Written informed consent was obtained from the patient's parents or legal guardians for publication of this case report and accompanying images. A copy of the written consent is available for review by the editorial office of this journal.

Open Access Statement: This is an Open Access article distributed in accordance with the Creative Commons Attribution-NonCommercial-NoDerivs 4.0 International License (CC BY-NC-ND 4.0), which permits the noncommercial replication and distribution of the article with the strict proviso that no changes or edits are made and the original work is properly cited (including links to both the formal publication through the relevant DOI and the license). See: https://creativecommons.org/licenses/by-nc-nd/4.0/. 


\section{References}

1. Van Praagh R, Van Praagh S. Persistent fifth arterial arch in man. Congenital double-lumen aortic arch. Am J Cardiol 1969;24:279-82.

2. Gupta SK, Gulati GS, Anderson RH. Clarifying the anatomy of the fifth arch artery. Ann Pediatr Cardiol 2016;9:62-7.

Cite this article as: $\mathrm{Li} \mathrm{X,} \mathrm{Li} \mathrm{J,} \mathrm{Qin} \mathrm{W,} \mathrm{Zhang} \mathrm{R.} \mathrm{Surgical} \mathrm{repair}$ of persistent fifth aortic arch coarctation and interrupted fourth aortic arch without cardiopulmonary bypass: a case report. Transl Pediatr 2022;11(2):306-310. doi: 10.21037/tp-21-350
3. Gerlis LM, Ho SY, Anderson RH, et al. Persistent 5 th aortic arch--a great pretender: three new covert cases. Int J Cardiol 1989;23:239-47.

4. Weinberg PM. Aortic arch anomalies. J Cardiovasc Magn Reson 2006;8:633-43.

5. Cetrano E, Polito A, Trezzi M, et al. Neonatal Repair of Persistent Fifth Aortic Arch Coarctation and Interrupted Fourth Aortic Arch. Ann Thorac Surg 2017;103:e475-7. 